\section{AB0196 \\ ENDOPLASMIC RETICULUM STRESS IN SYSTEMIC} SCLEROSIS

\section{S. O'reilly. Life sciences, Northumbria University, Newcastle Upon Tyne, UK}

Background: Systemic sclerosis is an autoimmune connective tissue disease in which their is inflammation and skin fibrosis. Currently there is no disease modifiying treatment due to the limited understanding of the pathogenesis of the disease. Endoplasmic recticulum (ER) stress, characterised by misfolded proteins, can be induced by a variety of stressors such as redox imbalanace and calcium depletion. This activation of ER stress by whatever trigger results in activation of an evolutionary conserved cell sensors and a resulting signalling cascade to help restore homeostasis. It is suggested in other fibrotic diseases that ER stress is prominent. Objectives: The aim of this study is to determine the role of ER stress in Systemic Sclerosis.

Methods: Healthy dermal fibroblasts where cultured in vitro and stimulated with the ER stress inducer thaspigargin and in some experiments with small interfering RNA to X-Box binding protein-1 or scramble controls at the matched concentration. Cell were then lysed and subjected to western blotting of XBP-1, IRE-alpha, ATF-6, collagen-1 and alpha tubulin for a loading control. In some experiments the dermal fibroblasts were treated with ER stress and 4-phenylbutric acid to inhibit ER stress and makers measured. q-RT-PCR was performed for Fli-1 and $18 S$ using specific primers and subjected to real time with SYBR green and normalised to $18 \mathrm{~S}$.

Results: ER stress mediated by thaspigargin results in activation of classical ER stress pathways. Inhibition of these pathways through small interfering RNA results in attenuation of collagen expression in dermal fibroblasts. This was also the case with dermal fibroblasts treated with the chemical inhibitor 4-phenylbutric acid. The epigenetic modifier Fli- 1 is reduced after ER stress. This is known to act as a brake on collagen regulation.

Conclusions: ER stress induced collagen accumulation and could be blocked by chemical and genetic reduction of XBP-1. Mechanistically this could be due to reduced Fli-1 therby releasing the brake on collagen 1 expression. Modulation of ER stress via chemical inhibitors could be a promising new treatment in SS.

Disclosure of Interest: None declared

DOI: 10.1136/annrheumdis-2018-eular.6443

\section{AB0197 METALLOPROTEINASE-7 AS AN EARLY MARKER OF LUNG DAMAGE AMONG POLYMYOSITIS AND DERMATOMYOSITIS PATIENTS}

V. Kmyta ${ }^{1}$, E. Prystupa ${ }^{2}$, L. Prystupa ${ }^{1}$, A. Kovchun ${ }^{1} .{ }^{1}$ internal medicine department posgraduate education, Sumy State University, Sumy, ${ }^{2}$ Lviv State University of Physical Culture, Lviv, Ukraine

Background: Interstitial lung disease (ILD) can complicate the course of polymyositis/dermatomyositis (PM/DM) almost in the half of patients and represents as a high risk factor of mortality among such cohort of patients from chronic pulmonary insufficiency. Lung function monitoring and chest high resolution computer tomography (HRCT) are obligatory methods of investigation among PM/DM patients. However, these methods allow to determine already formed interstitial changes in the lungs. Therefore, there is a need for biomarkers to seek early changes of lung tissue, what allows to prescribe basic treatment in time, encountering its side effects.

Metalloproteinase 7 (MMP-7) reflect lung damage and can also be an early biomarker of ILD which complicates PM/DM. It was early reported that $-181 \mathrm{~A} / \mathrm{G}$ (rs11568818) polymorphism in MMP-7 promoter modulates gene expression and plays pivotal role in the MMP-7 upregulation in that way affects ILD progression. Here, we evaluated the impact of $-181 \mathrm{~A} / \mathrm{G}$ polymorphism in MMP-7 promoter activity and its association with MMP-7 elevation.

Objectives: Our study was aimed to analyse the level of MMP-7 as an early marker of lung damage among PM/DM patients and also probable influence of rs11568818 on the MMP-7 elevation.

Methods: 17 patients with PM/DM have been observed in the rheumatology department with primary established diagnosis, 9 patients among them has proved diagnosis of ILD with HRCT. All patients have been examined according to the recommended EULAR standards and paraneoplastic reaction have been excluded. Patients have been divided into 2 groups, 1 st group include 9 patients with $\mathrm{PM} / \mathrm{DM}$ complicated with ILD, 2nd -8 patients with isolated PM/DM. Control group included 17 healthy volunteers. MMP-7 level was assayed by the enzyme immunoassay system in the blood serum. $-181 \mathrm{~A} / \mathrm{G}$ ( $\mathrm{rs} 11568818$ ) polymorphism was genotyped by polymerase chain reaction restriction fragment length polymorphism (PCR-RFLP) method. All statistical calculations were done using SPSS software 21.0.
Results: Results. Mean age of patients of the 1 st group $-48,44 \pm 2,74$, 2nd $54,25 \pm 2,55$, control group $-49,0 \pm 2,4(\mathrm{p}=0,33)$. DM have been established in 7 patients and PM - 10. Mean level of MMP-7 in the 1st group was 4,02 $\pm 1,58$ (C $95 \% 2,81-5,24)$, 2nd $-1,43 \pm 0,2(\mathrm{Cl} 95 \% 0,93-1,92)$, control group - 1,3 $\pm 0,75$ $(F=30,87, p<0,001)$. It was determined that the level of MMP-7 was positively correlated with Anti-Jo1 antibodies $(r=0,82, p=0,007)$ and it was higher among PM/ DM patients complicated with ILD $(p=0,001)$. Analysis of genotypes frequency AA/AG/GG with regard to rs 11568818 polymorphism, shows no significant distribution $(\mathrm{p}=0,984)$ and is following in the 1 st group $-66,7 \% / 22,2 \% / 11,1 \%$ and $62,5 \% / 25 \% / 12,5 \%$ - in the 2 nd, in the control group - 70,6\%/17,6\%/11,8\% respectively. The analysis of the connexion between studied genetic polymorphism with the level of MMP-7 didn't show any interdependence $(p=0,771)$.

Conclusions: The level of MMP-7 is higher among the 1st group, in comparison with 2nd and control groups. Positive correlation connexion between the level of MMP-7 and Anti-Jo1 antibodies among PM/DM patients with ILD was found. The difference between genotypes distribution according to the rs 11568818 gen polymorphism depending on existence of ILD and MMP-7 level is absent. Taking into account the results, we can admit that MMP-7 is a perspective marker of lung tissue damage among PM/DM patients.

Disclosure of Interest: None declared

DOI: 10.1136/annrheumdis-2018-eular.7229

\section{AB0198 BIOLOGICAL PROPERTIES OF URINE-STEM CELLS AND THERAPEUTIC EFFECT ON SYSTEMIC SCLEROSIS FIBROSIS}

Y. Yang ${ }^{1}$, A. Xiong ${ }^{2}$, Q. Zhang ${ }^{1}$, Y. Luo ${ }^{1}$, Q. Xie ${ }^{1}$, Y. Liu ${ }^{1} .{ }^{1}$ Department of Rheumatology and Immunology; ${ }^{2}$ West China Hospital of Sichuan University, Chengdu, China

Background: Because of the lack of effective treatment of systemic sclerosis (SSc), cellular therapy is considered as a salvage option. ${ }^{1-4}$ Mesenchymal stem cells (MSCs) are gaining attentions in the field of cell therapy of SSc. However current isolation methods of MSCs are all invasive and challenging. ${ }^{5}$ Some studies have reported the isolation from urine recently, and definition of urine-derived stem cells (USCs). ${ }^{6}$ The collection of USCs is noninvasive that could be a desired resource of MSC. So far, the information of therapeutic effect on SSc is limited. Objectives: We aimed to explore the biological characterizations of USCs and investigate the therapeutic effect on murine SSc model.

Methods: USCs were isolated and cultivated from sterile urine samples of healthy adult individuals. The related cell markers were examined by flow cytometry. The differentiation potentials were observed in adipogenic, osteogenic and chondrogenic medium, respectively. SSc murine models were conducted by daily intradermal injections of bleomycin and were further divided as treated and untreated group. Also, the healthy control group was conducted by daily injection of phosphate buffered saline (PBS). Treated group received an infusion of $2.5 \times$ $10^{5}$ USCs in the tail vein twice in one week after the 3 week modelling. Skin samples were obtained one week after the treatment. Hematoxylin-eosin and Masson staining were accomplished to observe the skin thickness and the hydroxyproline content was detected by hydroxyproline kit. The relative expression of collagen type I alpha 1 chain (Col1-a1), alpha-smooth muscle actin ( $\alpha$-SMA), and fibronectin $1(\mathrm{Fn}-1)$ were detected by real-time quantitative PCR.

Results: The morphology of USCs was spindle-shaped. They express CD73, CD90, and CD105 but CD34, CD45, CD19, CD11b, or HLA-DR. USCs possessed the abilities to differentiate into adipocytes, osteoblasts, and chondrocytes. In USCs treated group, the skin thickness $(\mathrm{p}=0.031)$ (Figure1A), the deposition of collagen in HE and Masson trichrome-staining $(p=0.007)$ (Figure1B), and Col1-a1 gene expression $(p=0.010)$ (Figure1C) were significantly reduced in comparison with untreated group and were close to healthy controls.
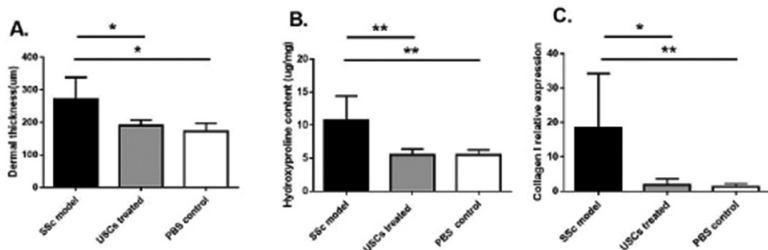

Abstract AB0198 - Figure 
Conclusions: USCs can be isolated from adult sterile urine. They possess the multipotent differentiation abilities and displays a therapeutic effect on bleomycininduced skin fibrosis and collagen synthesis.

\section{REFERENCES:}

[1] Gabrielli A, Avvedimento EV, Krieg T. Scleroderma. N Engl J Med 2009;360:1989-2003.

[2] Verrecchia F, Laboureau J, Verola O, et al. Skin involvement in scleroderma-where histological and clinical scores meet. Rheumatology 2007;46:833-841.

[3] Fleming JN, Nash RA, McLeod DO, et al. Capillary regeneration in scleroderma: Stem cell therapy reverses phenotype? PLoS One 2008;3:e1452.

[4] Aschwanden M, Daikeler T, Jaeger KA, et al. Rapid improvement of nailfold capillaroscopy after intense immunosuppression for systemic sclerosis and mixed connective tissue disease. Ann Rheum Dis 2008:67:10571059.

[5] Le Blanc K, Pittenger M. Mesenchymal stem cells: progress toward promise. Cytotherapy 2005;7:36-45.

[6] Zhang $\mathrm{Y}$, McNeill E, Tian $\mathrm{H}$, et al. Urine derived cells are a potential source for urological tissue reconstruction [J]. J Urol 2008;180:2226-2233.

Disclosure of Interest: None declared

DOI: 10.1136/annrheumdis-2018-eular.4359

\section{Rheumatoid arthritis - prognosis, predictors and outcome}

\section{AB0199 ENDOCAN LEVELS AND SUBCLINICAL ATHEROSCLEROSIS IN PATIENTS WITH RHEUMATOID ARTHRITIS}

G. Tuzcu', A.U. Uslu², A. Tuzcu ${ }^{3}$, R. Aydogan Baykara ${ }^{4}$, A. Omma ${ }^{5}$, A. Kucuk ${ }^{6}$. ${ }^{1}$ Radiology, Balikesir State Hospital, Balıkesir, ${ }^{2}$ Internal Medicine, Yunus Emre State Hospital, Eskisehir, ${ }^{3}$ Biochemistry, Balıkesir State Hospital, Balıkesir, ${ }^{4}$ Physical Medicine and Rehabilitation, Malatya Education and Research Hospital, Malatya; ${ }^{5}$ Rheumatology, Ankara Numune Training and Research Hospital, Ankara; ${ }^{6}$ Rheumatology, Necmettin Erbakan University, Konya, Turkey

Background: Rheumatoid arthritis (RA) is an inflammatory autoimmune disease with unknown etiology. Accelerated atherosclerosis (AS) and AS with heart disease are among the major causes of morbidity and/or mortality in RA. Endothelialspecific molecule 1 (endocan) is a potential indicator of vascular events and is expressed in response to inflammatory mediators in endothelial cells. Carotid intima media thickness (cIMT) is used to detect early signs of AS but also progression in cardiovascular diseases related to AS.

Objectives: The aim of the present study is to evaluate the relationship of serum endocan levels with RA and cIMT as a candidate marker of diseases to be used in clinical practice.

Methods: The study was conducted between June 2012 and March 2013 at the Rheumatology Clinics of Necmettin Erbakan Meram Medical School, Turkey. Thirty nine ${ }^{39}$ RA patients, diagnosed according to the 1987 criteria of the American College of Rheumatology, and 30 age-and sex-matched healthy subjects as the control group were included in this study.

\begin{tabular}{|c|c|c|c|}
\hline & $\begin{array}{c}\text { RA patients } \\
(\mathrm{n}=39) \\
(\mathrm{mean} \pm \mathrm{SD})\end{array}$ & $\begin{array}{c}\text { Controls } \\
(n=30) \\
(m e a n \pm S D)\end{array}$ & $P$ value \\
\hline$\overline{\text { Age (years) }}$ & $47.7 \pm 8.8$ & $43.0 \pm 10.8$ & 0.057 \\
\hline $\begin{array}{l}\text { Gender (M/F), n } \\
(\%)\end{array}$ & $\begin{array}{c}33(84.6) / 6 \\
(15.4)\end{array}$ & $\begin{array}{c}21(70) / 9 \\
(30)\end{array}$ & 0.238 \\
\hline BMI $\left(\mathrm{kg} / \mathrm{m}^{2}\right)$ & $28.0 \pm 4.3$ & $27.1 \pm 5.1$ & 0.443 \\
\hline ESR $(\mathrm{mm} / \mathrm{h})$ & $28.56 \pm 16.16$ & $18.70 \pm 12.27$ & 0.005 \\
\hline CRP $(\mathrm{mg} / \mathrm{dL})$ & $0.55 \pm 0.54$ & $0.42 \pm 0.55$ & 0.336 \\
\hline $\mathrm{TC}(\mathrm{mg} / \mathrm{dL})$ & $198.28 \pm 48.15$ & $\begin{array}{r}165.43 \\
\pm 30.59\end{array}$ & 0.001 \\
\hline $\mathrm{TG}(\mathrm{mg} / \mathrm{dL})$ & $153.58 \pm 93.02$ & $\begin{array}{r}132.73 \\
\pm 55.74\end{array}$ & 0.252 \\
\hline LDL-c (mg/dL) & $123.02 \pm 44.88$ & $\begin{array}{r}118.81 \\
\pm 24.76\end{array}$ & 0.622 \\
\hline $\begin{array}{l}\mathrm{HDL}-\mathrm{c}(\mathrm{mg} / \mathrm{dL}) \\
\mathrm{CIMT}(\mathrm{mm})\end{array}$ & $\begin{array}{c}50.43 \pm 10.18 \\
0.63 \pm 0.17\end{array}$ & $\begin{array}{c}42.12 \pm 8.18 \\
0.51 \pm 0.12\end{array}$ & $\begin{array}{c}<0.001 \\
0.001\end{array}$ \\
\hline Endocan & $14.11 \pm 3.27$ & $12.10 \pm 2.92$ & 0.009 \\
\hline
\end{tabular}

RA, Rheumatoid arthritis; BMI, body mass index; cIMT, carotid intima media thickness; TC total cholesterol; TG, triglyceride; LDL-c, low density-lipoprotein cholesterol; HDL-c, high density-lipoprotein cholesterol; ESR; erythrocyte sedimentation rate; CRP, C-reactive protein

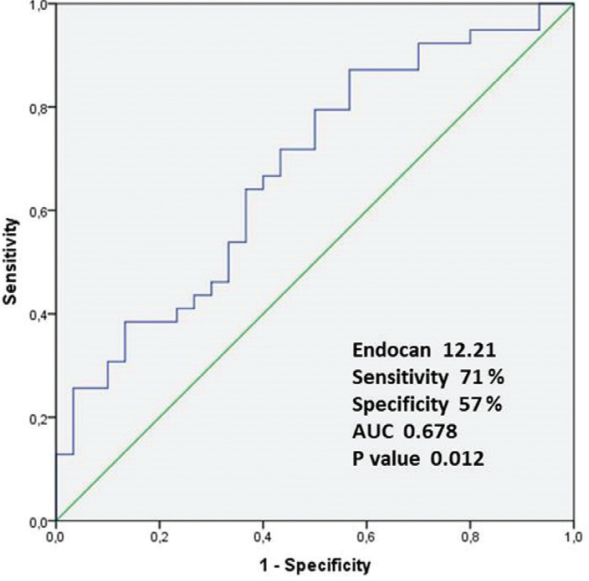

Abstract AB0199 - Figure 1

Results: No significant difference was detected between groups with respect to age, sex and body mass index. In the patient group the Endocan and cIMT values were found to be $14.11 \pm 3.27 \mathrm{ng} / \mathrm{mL}$ and $0.63 \pm 0.17 \mathrm{~mm}$, while in the control group they were $12.10 \pm 2.92 \mathrm{ng} / \mathrm{mL}$ and $0.51 \pm 0.12 \mathrm{~mm}$, the Endocan and cIMT values were significantly higher in the patient group ( $p=0.009$ and $p=0.001$, respectively). Positive correlations was found between Endocan, cIMT and Disease Activity Score of 28 joints $(p=0.008$ and $p=0.029$, respectively). When assessing the endocan levels of RA patients in the study population, cut off value of 12.21 with sensitivity of $71 \%$, specificity of $57 \%$ and $p=0.012$ (area under curve: $0.678,95 \%$ confidence interval (Cl) $0.555-0.805$ ) were observed according to ROC curve analysis.

Conclusions: Endocan might be a useful marker to evaluate atherosclerotic lesions in patients with RA and also to assess disease severity.

Disclosure of Interest: None declared

DOI: 10.1136/annrheumdis-2018-eular.4656

\section{$\mathrm{AB} 0200$ \\ FACTORS ASSOCIATED WITH FUNCTIONAL CAPACITY IN A BRAZILIAN COHORT OF PATIENTS WITH RHEUMATOID ARTHRITIS: RESULTS FROM THE " REAL "STUDY}

A.A.V. Pugliesi ${ }^{1}$, E.D.A. Macedo ${ }^{1}$, M.B. Bertolo ${ }^{1}$, R. Giorgi ${ }^{2}$, S. Radominski ${ }^{3}$ I. Pereira ${ }^{4}$, M.F. Guimaraes ${ }^{5}$, P. Louzada Jr ${ }^{6}$, M.D.F. Cunha ${ }^{7}$, K. Bonfiglioli ${ }^{8}$, C. Brenol ${ }^{9}$, L.M.H. Mota ${ }^{10}$, G. Castelar-Pinheiro ${ }^{11}$. ${ }^{1}$ Internal Medicine, Rheumatology Unit, Universidade Estadual de Campinas, Campinas; ${ }^{2}$ Instituto de Assistência Médica ao Servidor Público Estadual, São Paulo; ${ }^{3}$ Universidade Federal do Paraná, Curitiba; ${ }^{4}$ Universidade Federal de Santa Catarina, Florianopolis; ${ }^{5}$ Universidade Federal de Minas Gerais, Belo Horizonte; ${ }^{6}$ Universidade de São Paulo - Ribeirão Preto, Ribeirão Preto; ${ }^{7}$ Universidade Federal do Pará, Pará; ${ }^{8}$ Universidade de São Paulo, São Paulo; ${ }^{9}$ Universidade Federal do Rio Grande do Sul, Rio Grande do Sul; ${ }^{10}$ Universidade de Brasilia, Brasilia; ${ }^{11}$ Universidade Federal do Rio de Janeiro, Rio de Janeiro, Brazil

Background: Rheumatoid arthritis (RA) is associated with impairments in func tionality, affecting aspects such as physical capacity, independence, menta health, social and professional life. Health Assessment Questionnaire-Disability Index (HAQ-DI) is a validated tool for assessing functional capacity in RA patients. A simple questionnaire with a score of 0 to 3 is applied, with an inverse relationship between grade and functionality. Previous studies have shown worse functional indexes in patients with high disease activity and established joint damage. Objectives: To relate clinical, laboratory and therapeutic aspects with HAQ-DI in a large cohort of Brazilian patients.

Methods: A prospective, multicenter cohort study ("REAL" Study) involving 11 Brazilian centres specialised in the treatment of RA patients. All patients were submitted to at least 3 clinical evaluations in a 12 month period. Only patients older than 18 years and classified as RA according to 1987 (ACR) or 2010 (ACR/ EULAR) criteria were evaluated. HAQ-DI was applied for assessing functiona capacity, and the results were analysed for association with clinical, laboratory and therapeutic elements. Comparison between groups was performed using Mann-Whitney or Kruskal-Wallis tests

Results: Overall, 1116 patients $(89.43 \%$ females, mean age $58 \pm 11$ years) took part in the study. Rheumatoid factor (RF) in high levels and bone erosion were both associated with higher HAQ-DI indexes ( $\mathrm{p}: 0.0244$ and $\mathrm{p}<0.0001$, respectively). Of all patients, $89.7 \%$ were using conventional synthetic disease-modifying antirheumatic drugs (DMARDs) and $36.5 \%$ were on biologic DMARDs or 